\title{
Ultraviolet Light Induced Photocatalytic Degradation of Phthalic Anhydride Using Aeroxide P-25 and Kronos
}

\author{
Anand Kulkarni ${ }^{1}$, Dhananjay Bhatkhande ${ }^{* 1}$ \\ ${ }^{I}$ Chemical Engineering Department, Vishwakarma Institute of Technology, Pune 411037, Maharashtra, India
}

\begin{abstract}
In this work, photocatalytic degradation of phthalic anhydride using Aeroxide P-25 and kronos 7050 was performed under external UV light source. The photocatalytic activity for both of the catalysts was investigated under external UV light source. The effect of various parameters such as catalyst loading, initial concentration and initial $p H$ of PAN on degradation was studied. The results showed that phthalic anhydride was degraded to $71 \%$ in 4 h using Aeroxide P-25 at pH 3.5 while $55 \%$ degradation was achieved by kronos 7050 at same conditions. It was observed that $51 \%$ degradation of PAN was achieved by photochemical route. Under UV+Visible light illumination, $83 \%$ of degradation of PAN was achieved using (C-doped $\mathrm{TiO}_{2}$ ) Kronos 7000 which proved to be the best among three catalysts. In this work the kinetic model $\left(-r_{A}=0.005 C^{4} 0.825\right.$ I $\left.{ }^{b}\right)$ was developed that satisfactorily described the photocatalytic degradation of phthalic anhydride across the different sets of experimental conditions and it was observed that the experimental data for different concentration of phthalic anhydride fit this equation.
\end{abstract}

Keywords: Aeroxide P-25, Kronos, phthalic anhydride, Photocatalyst, UV radiations.

\section{Introduction}

Today the living style and pattern has improved to a great extent owing to large-scale industrialization and urbanization. However this has occurred at the cost of environmental degradation. The resources are simultaneously getting depleted and polluted. Despite various treatment schemes by industries to combat pollution, the desired decrease in levels with respect to specific pollutants has not been achieved. Frequent upsets in the effluent stream limits have an impact on the effluent treatment plant which adds to the constraint of an efficient central treatment facility.

Ironically, water which is essential to sustain life, acts as a carrier of deadly diseases due to discharge from untreated industrial effluents. There is an urgent need to address this alarming increase in contamination of surface and ground water. [1] We can achieve this by acquiring expertise in pollution control strategies beyond the conventional methods and implementation of novel techniques for the treatment of industrial wastewater. [2-4] Water pollution caused by organic compounds has received worldwide attention due to their potentially toxic effects on environment.

Several important studies on photochemical degradation are reported for degradation of organic compounds. [5-7] $\mathrm{H}_{2} \mathrm{O}_{2} / \mathrm{UV}$ process can not use the solar light as a source of UV radiation due to the fact that the required UV energy for the photolysis of the oxidizer is not adequate in solar spectrum. [8]

It was previously demonstrated that degradation of various organic pollutants such as halogenated hydrocarbons, phenols, dyes, phthalates, organochloric pesticides was achieved using photocatalytic oxidation using $\mathrm{TiO}_{2}$, as photocatalyst in artificial UV source. [9-18]

$\mathrm{TiO}_{2}$ has been most widely used photocatalyst due its non-toxicity, high stability and costeffectiveness and it exhibits high photocatalytic activity in UV-light source. [19-20]

In this work, photocatalytic degradation of phthalic anhydride (PAN) was studied using Kronos 7050 and Aeroxide P-25 under UV light illumination and using Kronos 7000 under visible light illumination. The results of degradation by photocatalytic and photochemical route are also compared. Herein, PAN was selected as model pollutant for degradation study. It has wide applications in the production of phthalate plasticizers, unsaturated polymer resins and alkyd resins. Several industrial plants produce large amount of wastewater containing high concentration of phthalates causing the threat to the environment and health. Those compounds are endocrine disruptors and have carcinogenic and mutagenic effects on human health. [21-24] It also has toxic effects on human fertility and hormone prone cancers. [25] Several studies reported that phthalate esters (PAEs) are poorly degraded by conventional treatments. [26] Because of its large production and toxicity, there is strong need to develop the efficient process for the treatment of such contaminated water. Trabelsi et al. (2010) studied the degradation of phthalic anhydride using plasma chemical oxidation in presence of $\mathrm{Fe}$ (II), $\mathrm{Fe}$ (III) and $\mathrm{TiO}_{2}$ photocatalyst and investigated that upto $65 \%$ of degradation was achieved 
by this method. Bajt et al. (1993) studied the oxidation of phthalic anhydride using photo-Fenton process and reported $97 \%$ of degradation of PAN. Very few references are available on the degradation of PAN using AOPs. This work includes photocatalytic degradation of PAN using Kronos and Aeroxide P-25 which was performed for the first time. In this work the effect of catalyst loading, initial concentration and $\mathrm{pH}$ on degradation of PAN was investigated. In addition to the experimental work, kinetic model was employed to predict the photocatalytic degradation of PAN and validated for the experimental data.

\section{Experimental}

\subsection{Materials}

Aeroxide P-25 $\mathrm{TiO}_{2}$ with average particle size of $20 \mathrm{~nm}$ and BET surface area $60 \mathrm{~m}^{2} \mathrm{~g}^{-1}$ was used as photocatalyst. Aeroxide P-25 was supplied from GEM Corporation, Mumbai (INDIA). Kronos with $250 \mathrm{~m}^{2} \mathrm{~g}^{-1}$ BET surface area was provided by Kronos International Inc., Germany. Phthalic anhydride was procured from E Merc India Ltd, Mumbai (India). Hydrogen peroxide (30\%) was supplied by Loba chemie (P) Ltd, Mumbai.

\subsection{Method}

\subsubsection{Characterization}

The UV-Vis absorption spectra was obtained for Kronos 7000, using a UV-Vis spectrophotometer (Shimadzu 2501 PC) mounted with an integrating sphere accessory (ISR1200) using $\mathrm{BaSO}_{4}$ as reference standard.

\subsubsection{Photocatalytic degradation of PAN in external artificial UV-light source}

Photocatalytic experiments were carried in the quartz reactor of $800 \mathrm{~cm}^{3}$ capacity, with centrally mounted air sparger, so as to ensure photocatalyst in suspension during experimentation, surrounded by cooling coil. The temperature of the reaction was maintained at room temperature by circulating chilled water through the coil to avoid any loss of solution evaporation. $500 \mathrm{~cm}^{3}$ PAN solution was taken for the experimentation with known weight of the photocatalyst. Intensity meter (Sun meter, Sun associates, India) was used to measure the average intensity of external visible light source and was found to be $80 \mathrm{~W} / \mathrm{m}^{2}$. In case of photocatalytic degradation using UV, UV lamp of 125 watt was placed at the bottom of the reactor so as to ensure uniform illumination.

The catalyst optimization for Kronos 7050 and Aeroxide P- 25 was performed by varying the catalyst loading from 0.1 to $0.4 \mathrm{~g} \mathrm{~L}^{-1}$ in each case. The effect of initial concentrations of PAN was studied on PAN degradation. The effect of initial $\mathrm{pH}$ of the solution on degradation was studied at different $\mathrm{pH}$ conditions $(1.2$, $2.5,3.2$ and 8.5). The samples were withdrawn at regular time interval of 60 minutes using syringe and analyzed with High Pressure Liquid Chromatograph [Shimadzu] using C8-column. The mobile phase composition was $0.1 \%$ formic acid in water and acetonitrile with a flow rate of $1.0 \mathrm{ml} / \mathrm{min}$.

\section{Results and discussion \\ 3.1 Photocatalytic degradation of PAN in external artificial UV light source \\ 3.1.1 Catalyst optimization}

The effect of catalyst loading on degradation of PAN was evaluated using both the photocatalysts namely Aeroxide P-25 and Kronus-7050. Fig. 1 and 2 illustrates the optimization of catalyst loading for Aeroxide P-25 and Kronos 7050 respectively. The results showed that initially photocatalytic degradation increases with increase in catalyst loading till it reaches the optimal loading $\left(0.3 \mathrm{~g} \mathrm{~L}^{-1}\right.$ Aeroxide P-25 and 0.25 $\mathrm{g} \mathrm{\textrm {L } ^ { - 1 }}$ Kronos 7050) and further increase in catalyst loading reduces degradation due to shielding effect hindering the light transmission through the solution causing the less generation of electrons and positive holes and thus reducing the photocatalytic activity. [10, 29-31]

$$
<\text { Figure } 1><\text { Figure } 2>
$$

\subsubsection{Effect of initial concentration of PAN}

The effect of initial concentration of PAN on photocatalytic degradation at different initial concentrations $(100,200,250,300 \mathrm{ppm})$ was evaluated and from Fig. 3 it was investigated that with the increase in initial concentration for PAN, the rate of degradation decreases, as Aeroxide P-25 loading, rate of generation of ${ }^{\bullet} \mathrm{OH}$ radicals, illumination intensity and time are constant during photodegradation.

$<$ Figure 3> 


\subsubsection{Effect of initial $\mathrm{pH}$ of PAN solution}

To evaluate the effect of $\mathrm{pH}$ on degradation, photocatalytic degradation of PAN was carried out at different $\mathrm{pH}$ conditions $(1.2,2.5,3.5,8.5)$. The $\mathrm{pH}$ was adjusted by perchloric acid for acidic solutions and 0.1 $\mathrm{NaOH}$ for basic solutions. From fig. 4 it was observed that $52.5 \%$ and $45.9 \%$ degradation of PAN was achieved in $4 \mathrm{~h}$ at $\mathrm{pH} 2.5$ and $\mathrm{pH} 8.5$ respectively. At $\mathrm{pH} 3.5$ maximum degradation of PAN (71\%) was achieved. The zero point charge of $\mathrm{TiO}_{2}$ is at $\mathrm{pH} 6$ and $\mathrm{TiO}_{2}$ is of amphoteric in nature. Due to this, in both acidic and alkaline range photocatalytic degradation decreases. This is in agreement with results of Mangrulkar et al. (2011) who have used N- doped $\mathrm{TiO}_{2}$.

$$
<\text { Figure 4> }
$$

\subsection{Photocatalytic activity of Aeroxide P-25 and Kronos (7050 and 7000)}

The photocatalytic degradation experiments were carried out at identical conditions using Aeroxide P25 and Kronos 7050 under external UV light source. It was observed that $71 \%$ and $55 \%$ degradation was achieved in case of Aeroxide P-25 and Kronos 7050 in $4 \mathrm{~h}$ respectively. Though Kronos 7050 has more surface area $\left(250 \mathrm{~m}^{2} \mathrm{~g}^{-1}\right)$ than Aeroxide P-25 $\left(60 \mathrm{~m}^{2} \mathrm{~g}^{-1}\right)$, it exhibited less degradation. From XRD patterns of Kronos 7050 , only anatase crystal phase was identified by its major (101) peak at $\left(2 \theta=25.5^{\circ}\right)$ whereas from literature it was observed that Aeroxide P-25 exhibited major peak of anatase (101) at $25.5^{\circ}$ and rutile phase (110) at $27.3^{\circ}$. [33] Anatase is more active crystalline form of $\mathrm{TiO}_{2}$, however the presence of rutile (30\%) in Aeroxide P-25 decreases the recombination of generated ${ }^{\bullet} \mathrm{OH}$ radicals which is responsible for greater photocatalytic activity. The presence of rutile form (30\%) in Aeroxide P-25 prevented the recombination of holes and electrons thus improving the performance of photocatalytic degradation. This justification is in agreement with Bhatakhande et al. (2004). Fig. 5 illustrates plot of $\ln (\mathrm{C} / \mathrm{Co}) \mathrm{v} / \mathrm{s}$ Time for Aeroxide P-25 and Kronos 7050.

$<$ Figure 5>

Photocatalytic degradation of PAN under visible light illumination was carried using Kronos 7000 (Cdoped $\mathrm{TiO}_{2}$ ). The UV-vis absorption spectra obtained for Kronos 7000 was shown in Fig. 6. It was observed that $83 \%$ of the degradation of PAN was achieved in $4 \mathrm{~h}$ and it proved to be more effective than Aeroxide P25. Compared to non doped photocatalyst (Aeroxide P-25), in case of C-doped $\mathrm{TiO}_{2}$ (Kronos 7000), there is intense absorption of visible light resulting in more photogenerated electrons and holes thereby increased photocatalytic activity. Also due to increased surface area there was more adsorption resulting in more absorption of energy enhancing the photocatalytic activity.

\section{$<$ Figure 6>}

Using HPLC analysis it was investigated that intermediates like salicylic acid, catechol, and benzoquinine were formed during degradation in very small quantities which are further oxidized.

\subsection{Comparison of photocatalytic and photochemical degradation of PAN under external UV source}

Photochemical degradation of PAN under external UV source was studied using stoichiometric amount of hydrogen peroxide $(30 \%)$ and $200 \mathrm{ppm}$ of PAN concentration. Fig. 7 shows that photochemical degradation is much lower as compared to photocatalytic degradation. By photochemical route $51 \%$ degradation of PAN was achieved in $4 \mathrm{~h}$ at same operating conditions and $\mathrm{pH} 3.5$.

$<$ Figure $7>$

Stasinakis et al. (2008) investigated that lower $\mathrm{pH}$ values ranging from 2.5-3.5 are usually preferred for the photochemical degradation however at very low $\mathrm{pH}$, hydrogen peroxide is stable and it forms oxonium ion $\left(\mathrm{H}_{3} \mathrm{O}^{+}\right)$which enables $\mathrm{H}_{2} \mathrm{O}_{2}$ electrophile to enhance its stability, decreasing the formation of hydroxyl radicals and thereby reducing the degradation rate. Anatoniou et al. (2010) have reported that since the UV lamps in the study emit light at a range of wavelengths $(300<<400 \mathrm{~nm})$ the activation of oxidants is believed to be caused by the emission spectra and not $\lambda_{\max }=365 \mathrm{~nm}$. The applied wavelength in the experiment was 365 $435 \mathrm{~nm}$ at which $\mathrm{H}_{2} \mathrm{O}_{2}$ has low absorption resulting in less degradation of model compound. In case of photochemical degradation, better results would have been obtained using UV source with shorter wavelength $(180-200 \mathrm{~nm})$. [3]

\subsection{Kinetic model development}

It was observed that photocatalytic degradation of PAN using Aeroxide P-25 and Kronos 7050 exhibited pseudo first order reaction.

Several recent reports claim that the photocatalytic degradation follows Langamuirs-Hinshewood model (L-H model) of kinetics. [29] However it is still a subject of debate that the validity of L-H model in photocatalytic degradation could be misconception without proper experimental evidences. In this work the 
objective was to establish a model that satisfactorily describes the photocatalytic degradation across a variety of experimental conditions which will useful for scale-up.

Considering first order reaction, the rate equation can be expressed as-

$-r_{\mathrm{A}}=-\mathrm{dC}_{\mathrm{A}} / \mathrm{dt}=\mathrm{k} \mathrm{C}_{\mathrm{A}}{ }^{\mathrm{a}} \mathrm{I}^{\mathrm{b}} \ldots \ldots \ldots \ldots \ldots \ldots \ldots \ldots . . \ldots \ldots \ldots+$ equation (1)

Where $-r_{A}$ : rate of reaction; $k$ : rate constant; $\mathrm{C}_{\mathrm{A}}$ : Concentration; I : intensity of light

$\ln \left(-\mathrm{r}_{\mathrm{A}}\right)=\ln \mathrm{K}+\mathrm{a} \ln \mathrm{C}_{\mathrm{A}}+\mathrm{b} \ln \mathrm{I} \ldots \ldots \ldots \ldots \ldots \ldots$ equation (2)

$\ln \left(-\mathrm{r}_{\mathrm{A} 1}\right)=\ln \mathrm{K}+\mathrm{a} \ln \mathrm{C}_{\mathrm{A} 1}+\mathrm{b} \ln \mathrm{I}_{1} \ldots \ldots \ldots \ldots \ldots \ldots \ldots \ldots .$. equation (3)

$\ln \left(-\mathrm{r}_{\mathrm{A} 2}\right)=\ln \mathrm{K}+\mathrm{a} \ln \mathrm{C}_{\mathrm{A} 2}+\mathrm{b} \ln \mathrm{I}_{2} \ldots \ldots \ldots \ldots \ldots \ldots \ldots . .$. equation (4)

During the experimentation considering, intensity of light source kept constant throughout he experiment, the modified form of equation becomes

$\ln \left[\left(-\mathrm{r}_{\mathrm{A} 1}\right) /\left(-\mathrm{r}_{\mathrm{A} 2}\right)\right]=\mathrm{a} \ln \left[\left(\mathrm{C}_{\mathrm{A} 1}\right) /\left(\mathrm{C}_{\mathrm{A} 2}\right)\right] \ldots \ldots \ldots \ldots \ldots \ldots . .$. equation $(5)$

$\mathrm{a}=\ln \left[\left(-\mathrm{r}_{\mathrm{A} 1}\right) /\left(-\mathrm{r}_{\mathrm{A} 2}\right)\right] / \ln \left[\left(\mathrm{C}_{\mathrm{A} 1}\right) /\left(\mathrm{C}_{\mathrm{A} 2}\right)\right] \ldots \ldots \ldots \ldots \ldots \ldots .$. equation $(6)$

Solving the above equations, model equation for photocatalytic degradation of PAN was derived as $\left(-r_{A}=\right.$ $0.005 \mathrm{C}_{\mathrm{A}}{ }^{0.825}$ ).

The experimental data for another set with different concentrations of PAN (100 ppm, $250 \mathrm{ppm})$ was tested for the above model equation (refer Fig. 8) and it was observed that the experimental data is fitted successfully for the developed model equation.

$<$ Figure $8>$

\section{Conclusion}

In this work, the comparative study was done for photocatalytic degradation of PAN using Kronos (7050 and 7000) and Aeroxide P-25 and by photochemical route. It was observed that catalyst loading and initial $\mathrm{pH}$ has significant effect on photocatalytic degradation. The presence of rutile form (30\%) in Aeroxide P-25 prevented the recombination of holes and electrons and showed higher photocatalytic activity than Kronos 7050 inspite of less surface area. It was observed that $71 \%$ and $55 \%$ of degradation was achieved in case of Aeroxide P-25 and Kronos 7050 in $4 \mathrm{~h}$ respectively under external UV light illumination. The applied wavelength in the experiment was 365-435 nm at which $\mathrm{H}_{2} \mathrm{O}_{2}$ has low absorption which may have caused the less degradation $(51 \%)$ of model compound by photochemical route whereas using Kronos 7000 under visible light illumination $83 \%$ of degradation was achieved.

The kinetic model for photocatalytic degradation of PAN was predicted successfully with the model equation $\left(-r_{\mathrm{A}}=0.005 \mathrm{C}_{\mathrm{A}}{ }^{0.825}\right)$ and the results confirmed that this model could be effectively predict the photocatalytic degradation of PAN and can be use for the scale up. UV light accounts only $4-8 \%$ in solar radiation and is not sufficient for activation of photocatalysts. There is need to develop the visible light induced photocatalysts such as Kronos 7000, so as to promote the photocatalytic treatment for full scale application in industries.

\section{Acknowledgments}

The authors are thankful to GEM Corporation (India) for providing Aeroxide P-25 for the experimentation. The authors are also thankful to Mr. S. Katavi (Clariant Chemicals Ltd.) and Kronos International Inc., Germany for providing the catalyst for research work.

\section{References}

[1]. A.A. Yawalkar, D. S. Bhatkhande, V. G. Pangarkar, and A.A.C.M. Beenackers, Solar assisted Photocatalytic and photochemical degradation of phenol, Journal of Chemtech Biotech, 76, 2001, 363-370.

[2]. Ksibi M., A. Zemzemi, and R. Boukchina, Photocatalytic degradability of substituted phenols over UV irradiated $\mathrm{TiO}_{2}$, Journal of Photochemistry and Photobiology, 159, 2003,. 61-70.

[3]. M. Italo, P. Paola, and S. B. Luca, Degradation of organic pollutants in water by photochemical reactors, Catalysis Today, 48, 1999, 315-321.

[4]. J.B. Rodolfo, R. Gerardo, M. A. Orlando, and E. C. Alberto, Photocatalytic reactors reaction kinetics in a flat plate solar simulator," Catalysis Today, 76, 2002, 161-175.

[5]. U. Bali, E. C. Catalkaya, and F. Sengul (2003) Photochemical degradation and mineralization of phenol: a comparative study, Jr. of Environmental Science and Health, 38, 2003, 2259-75.

[6]. F.J.Benitez, A.J. Beltran-Heredia and J.L. Acero, Oxidation of vanillic acid as a model of polyphenolic compounds in olive mill wastewaters. III. Combined UV radiation-hydrogen peroxide oxidation, Toxicol. Environ. Chem., 56, 1996, 199-210.

A.R. Dincer, N. Karakaya, E. Gunes and Y. Gunes Y. Removal of COD from oil recovery industry wastewater by the advanced oxidation processes (AOP) based on $\mathrm{H}_{2} \mathrm{O}_{2}$, Global NEST Journal, 10, 2008, 31-38.

[7]. M. Niaounakis and C.P. Halvadakis, Olive processing waste management - Literature review and patent survey, Elsevier, Amsterdam , 2nd edition, 2006.

D.Y. Goswami, Review of engineering developments of aqueous phase solar photocatalytic detoxification and disinfection processes, Journal of Solar energy Engineering, 119, 1997, 101-107.

[8]. M. Sixto, B. Julián, V. Alfonso, and R. Christoph, Photocatalysis with solar energy at a pilot-plant scale: an overview, Applied 
Catalysis B: Environmental, 37, 2007, 1-15.

[9]. A. T Cooper, D. Y. Goswami, and S. S. Block, Solar photochemical detoxification and disinfection for water treatment in tropical developing countries, Journal of Advances oxidation techniques, 3, 1998, 151-154.

[10]. D. S. Bhatkhande, V. G. Pangarkar, and A.A.C.M. Beenackers, Photocatalytic degradation for environmental applications-a review, Journal of chemical technology and Biotechnology, 77, 2001, 102-116.

[11]. D. S. Bhatkhande, V. G. Pangarkar, and A.A.C.M. Beenackers, Photocatalytic degradation of nitrobenzene using titanium dioxide and concentrated solar radiation: chemical effects and scale up, Water research, 37, 2003, 1223-1230.

[12]. J. Tseng, and C. Haung, Removal of chlorophenols from water by photocatalytic oxidation, Wat. Sci .Tech., 23, 1991, 377-387.

[13]. M. Noorjahan, M. Pratap, V. Durga, B. Lavédrine, P. Boule, and M. Subrahmanyam , Photocatalytic degradation of H-acid over a novel $\mathrm{TiO}_{2}$ thin film fixed bed reactor and in aqueous suspensions, Journal of Photochemistry and Photobiology A: Chemistry, 156, 2003, 179-187.

[14]. S. Maria, I. K. Dimitris, and E. V. Xenophon, Visible light-induced Photocatalytic degradation of Acid Orange 7 in aqueous $\mathrm{TiO}_{2}$ suspensions, Applied Catalysis B: Environmental, 47, 2004, 189-201.

[15]. [17] B. Bayarri, J. Gime'nez, D. Curco, and S. Esplugas, "Photocatalytic degradation of 2,4-dichlorophenol by $\mathrm{TiO}_{2} / \mathrm{UV}$ : Kinetics, actinometries and models," Catalysis Today, 101, 2005, 227-236.

[16]. R. Vinu, and M. Giridhar, "Environmental remediation by photocatalysis, Journal of the Indian Institute of Science, 90, 2010, 189-230.

[17]. M. Pelaez, A. Armah , A. A. Cruz, E. Stathatos, P. Falarasb, and D. D. Dionysiou, Visible light-activated N-F codoped $\mathrm{TiO}_{2}$ nanoparticles for the photocatalytic degradation of microsystin-LR in water, Catalysis Today, 144, 2009, 19-25.

[18]. M. Pelaez, P. Falarasb, V. Likodimos, A.G. Kontos, A. Armah A, A.A.le da.Cruz, O'shea K, and D.D. Dionysiou, Synthesis, structural characterization and evaluation of sol-gel-based $\mathrm{NF}^{-\mathrm{TiO}_{2}}$ films with visible light-photoactivation for the removal of microcystin-LR, Applied Catalysis B: Environmental, 99, 2010, 378-387.

[19]. N. Adhoum, and L. Monser, Removal of phthalate on modified activated carbon: Application to the treatment of industrial Wastewater, Sep.Pur.Technol., 38(3), 2004, 233-239.

[20]. C. Staples, D. Peterson, T. Parkerton, and W. Adam, The experimental fate of phthalate esters: A literature review, Chemosphere, 35(4), 1997, 667-749.

[21]. P.B. Hoyer, Reproductive toxicity: Current and future directions, J of Biochem Pharmacol, 62(12), 2001, 1557-1564.

[22]. L. Benzamin, W. Hawher, J. Muller, D. Leuscho, L. Temblay, and H. Chapman, Modeling of the fate of selected endocrine disruptors in a municipal wastewater treatment plant in South East Queensland. Australia., Chemosphere, 69(4), 2007, 644-654.

[23]. Vethaak A., J. Lahr, S. Schrap , A. Belfroid, G.B.J. Rijs, A. Geritsen, J. de. Boer, A. Bulde, G.C.M. Grinvis, R. Kuipar, J. Legler, T.A.T. Murk, W. Peijnenburg W, H.S.M. Verhaar, P. De Voogt, An integrated assessment of estrogenic contamination and biological effects in the aquatic environment of Netherlands, Chemosphere,59(4), 2005, 511-524.

[24]. J. Ejlertsson, M. Alnervik, S. Jonsson, and H. Svesson, Influence of water solubility, side-chain degradability and side-chain structure on the degradation of phthalic acid esters under methanogenic conditions, Environ. Sci. Technol, 31(10), 1997, 27612764.

[25]. S. Trabelsi, N. Oturan, N. Bellakhal, and M. Oturan, Electrochemical oxidation of phthalic anhydride in aqueous medium by electroFenton process, J. Environ. Eng. Manage. 19(5), 2009, 291-297.

[26]. O. Bajt, B. Sket, and J. Fagneli, The effect of semiconductor oxides on the photochemical degradation of phthalic and maleic anhydride in aqueous medium, Toxicology and Environmental Chemistry, 40, 1993, 267-273.

[27]. D. S. Bhatkhande, S. P. Kambale, S. B. Sawant, and V. G. Pangarkar, Photocatalytic and photochemical degradation of nitrobenzene using artificial ultraviolet light, Water research, 102, 2004, 283-290.

[28]. C. Chyow-San, S. Je-Lueng, C. Ching-Yuan, L. Cheng-Chung, and C. Chang-Tang, Degradation of di-n-butyl phthalate using photoreactor packed with $\mathrm{TiO}_{2}$ immobilized on glass beads, Journal of Hazardous Materials B., 137,2006, 1123-1129.

[29]. B.N. Narayanan, Y. Zahira, K. Ranjana, and C. Soumini, Photodegradation of Methyl orange over Zirconia doped TiO ${ }_{2}$ using solar energy, European Journal of Scientific Research, 28, 2009, 566-571.

[30]. P.A. Mangrulkar, S. P. Kamble, M. M. Joshi, J. S. Meshram, N. K. Labhsetwar, and S. S. Rayalu, Photocatalytic Degradation of Phenolics by N-Doped Mesoporous Titania under Solar Radiation, International Journal of Photoenergy. Article ID 78056210 (doi:10.1155/2012/780562), 2012.

[31]. R. Antony, and B. Viswanthan, Effect of surface area, pore volume and particle size of P25 titania on the phase transformation of anatase to rutile, Indian journal of Chemistry, 48A, 2009, 1378-1382.

[32]. A.S. Stasinakis, Use of selected advanced oxidation processes for wastewater treatment, Global NEST journal, 10,2008, 376-385.

[33]. M.G.Antonion, A.A.de la Cruz, and D.D. Dionysiou, Degradation of microsystin-LR using sulphide radicals generated through photolysis, thermolysis and e-transfer mechanism, Applied catalysis B: Environmental, 96, 2010, 290-298.

\section{Figure Captions:}

Figure 1.

Figure 2.

Figure 3.

Figure 4.

Figure 5.

Figure 6.

Figure 7.

Figure 8.
Effect of Catalyst loading for Aeroxide P-25

Effect of catalyst loading for Kronos 7050

Effect of initial concentration on degradation for Aeroxide P-25

Effect of $\mathrm{pH}$ on degradation for Aeroxide P-25

$\ln (\mathrm{C} / \mathrm{Co})$ vs. Time for Aeroxide P-25 and Kronos 7050

UV-vis absorbance of Kronos 7000

Photocatalytic and Photochemical Degradation of PAN

Test of a rate equation for different concentrations of PAN 


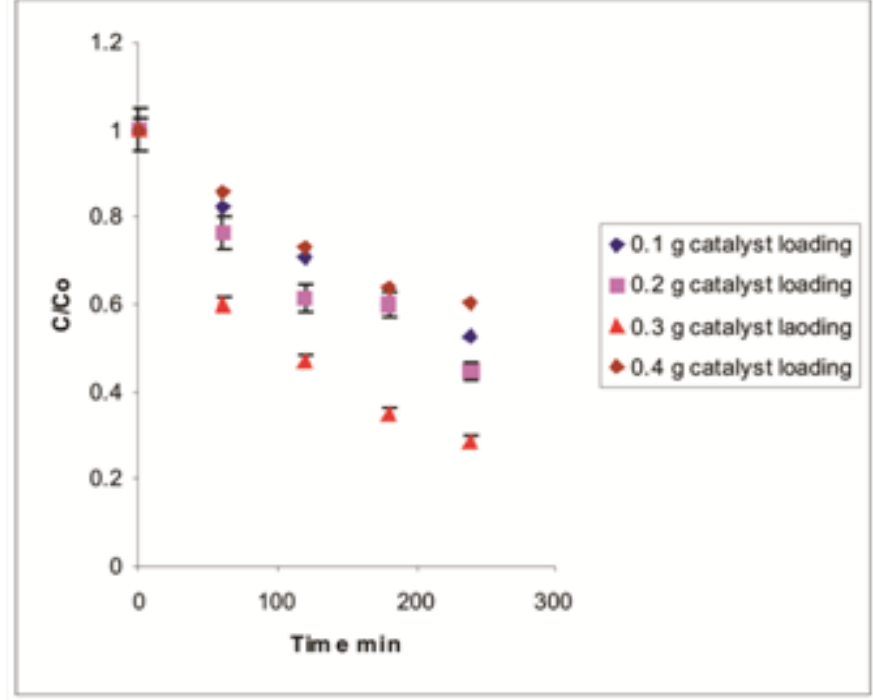

Figure 1

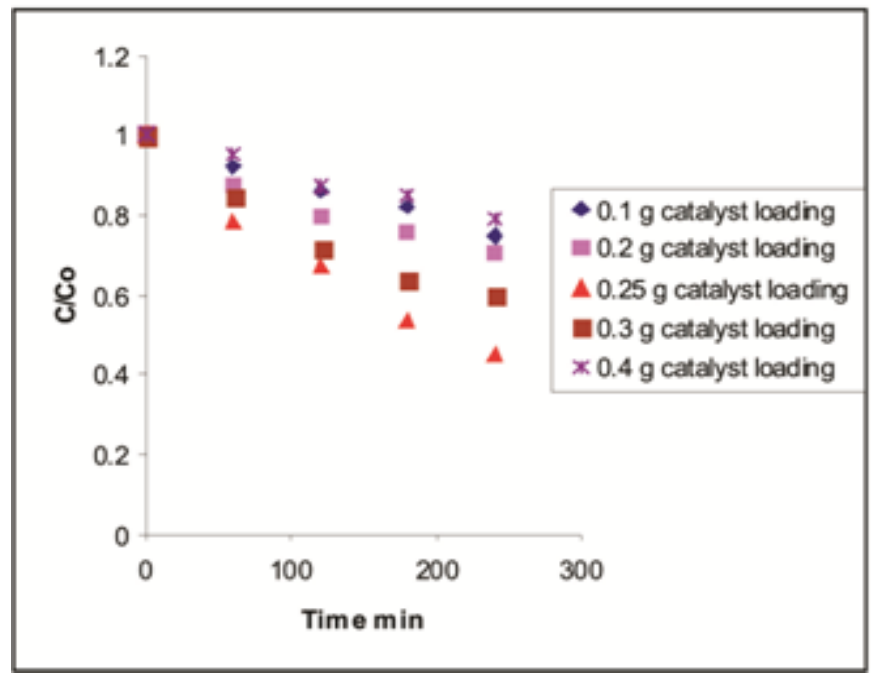

Figure 2

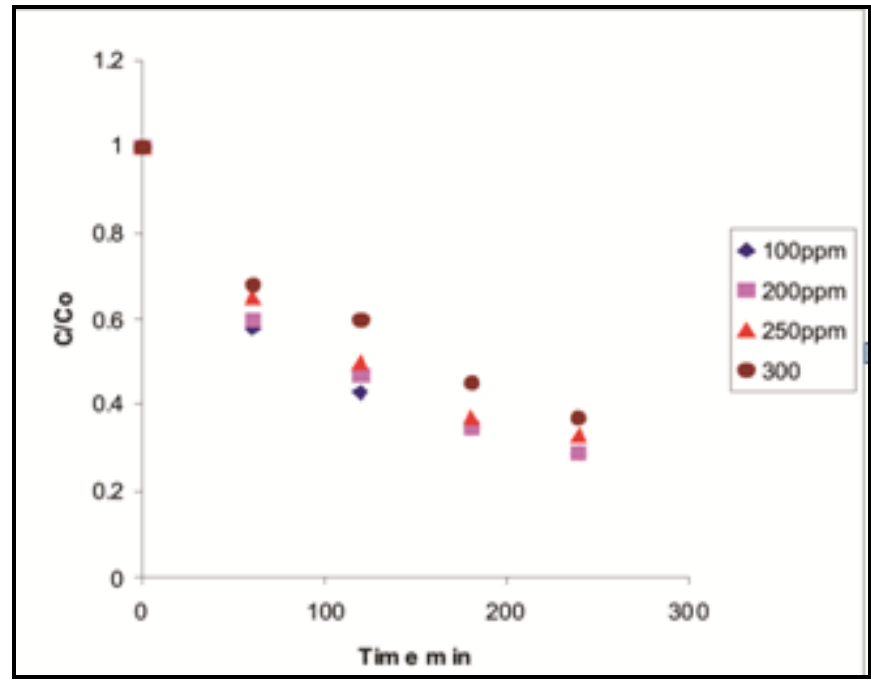

Figure 3 


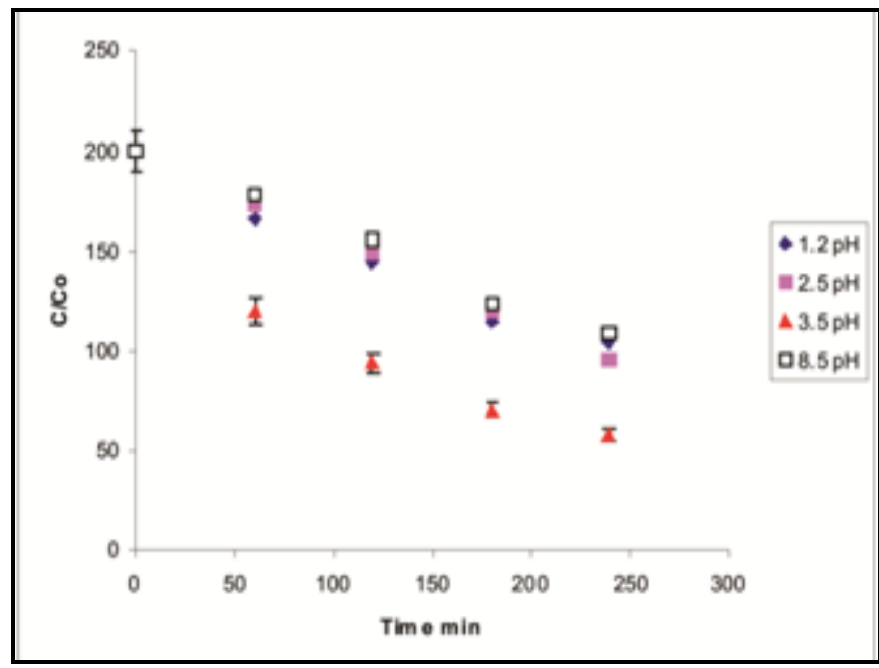

Figure 4

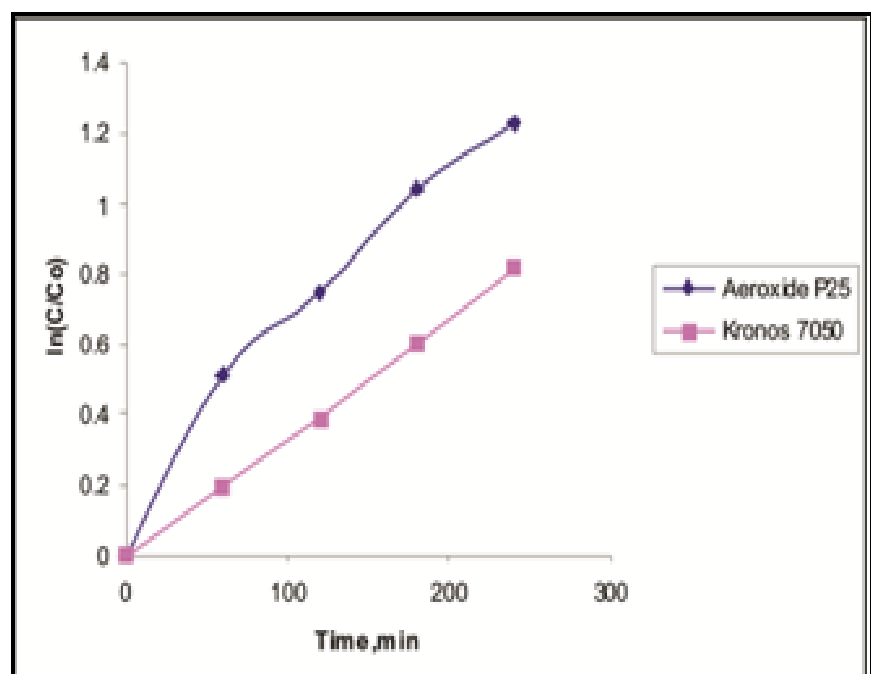

Figure 5

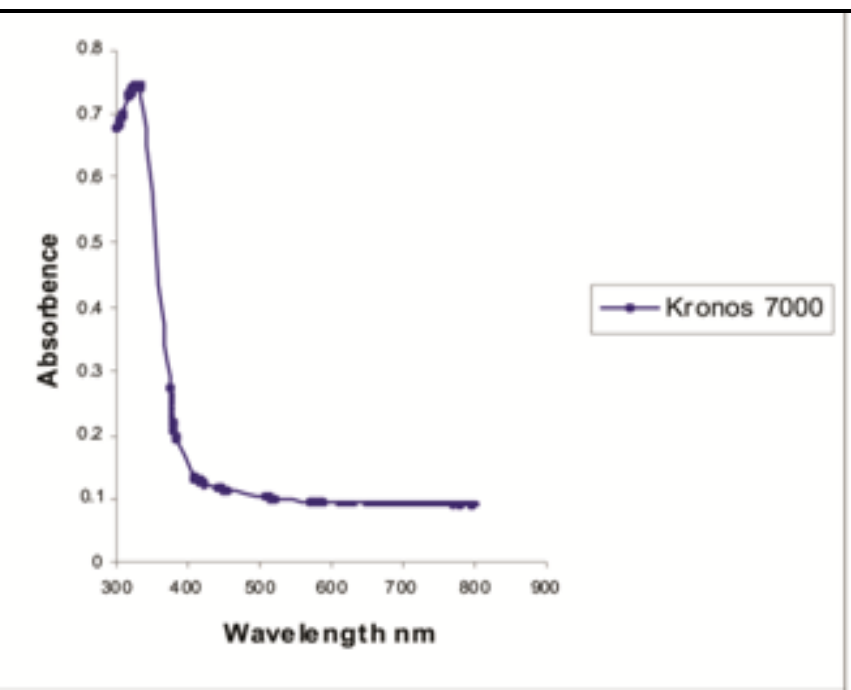

Figure 6 


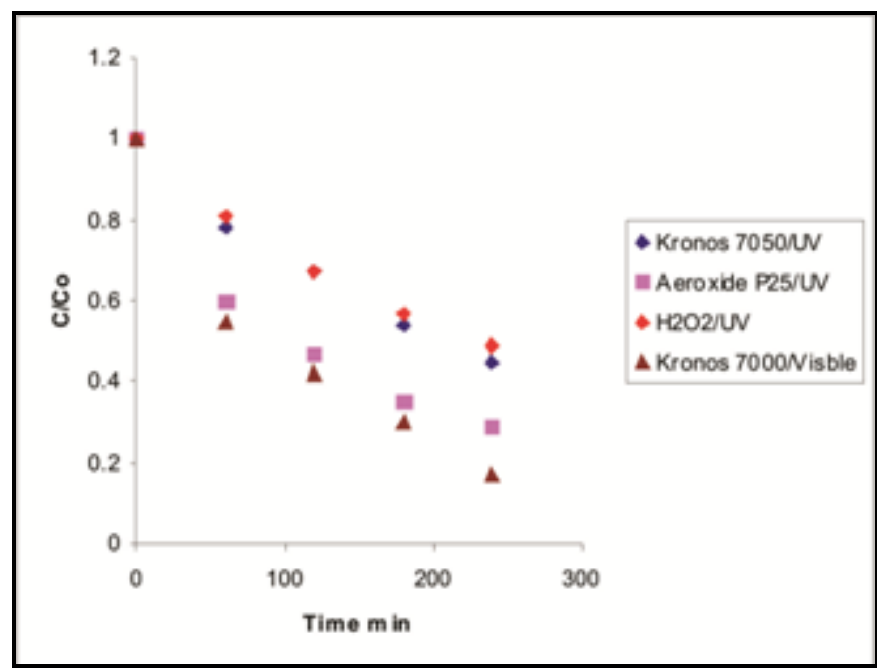

Figure 7

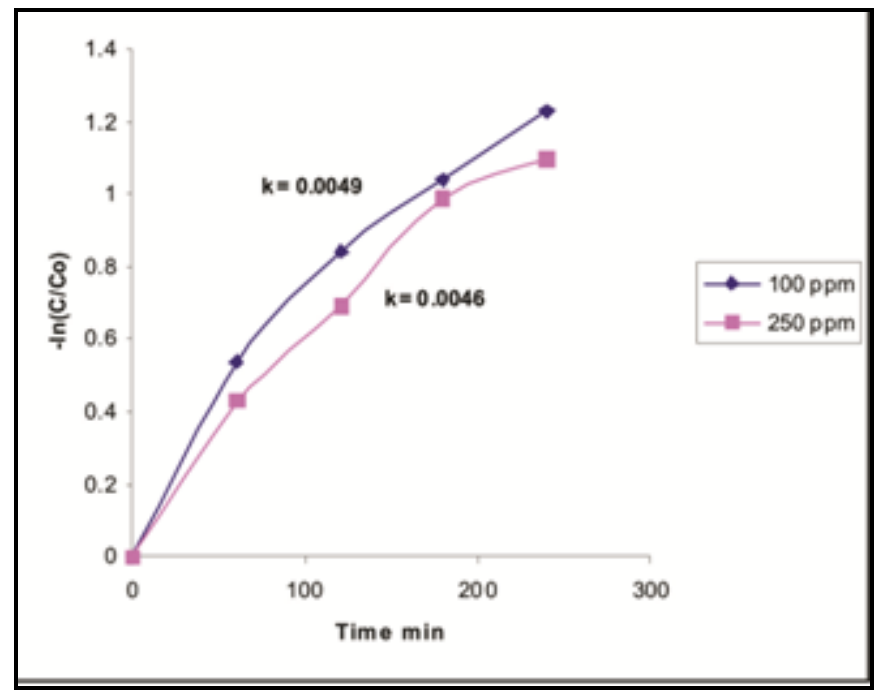

Figure 8 